\title{
Rehabilitation management of low back pain - it's time to pull it all together!
}

PERSPECTIVES

This article was published in the following Dove Press journal:

Journal of Pain Research

3 October 2017

Number of times this article has been viewed

\author{
Yannick \\ Tousignant-Laflamme ${ }^{1,2}$ \\ Marc Olivier Martel $^{3}$ \\ Anand $\mathrm{B}$ Joshi $^{4}$ \\ Chad E Cook ${ }^{5}$ \\ 'School of Rehabilitation, Faculty \\ of Medicine and Health Sciences, \\ Université de Sherbrooke, \\ Sherbrooke, QC, Canada; ${ }^{2}$ Clinicial \\ Research Center of the Centre \\ Hospitalier Universitaire de \\ Sherbrooke, Sherbrooke, QC, Canada; \\ ${ }^{3}$ Faculties of Dentistry \& Medicine, \\ McGill University, Montreal, QC, \\ Canada; ${ }^{4}$ Duke Health, Department of \\ Orthopaedic Surgery, Duke University \\ Medical Center, ${ }^{5}$ Doctor of Physical \\ Therapy Division, Duke University, \\ Durham, NC, USA
}

Correspondence: Yannick

Tousignant-Laflamme

School of Rehabilitation, Faculty of

Medicine and Health Sciences, Université de Sherbrooke, 300I, 12e Avenue Nord,

Sherbrooke, QC JIH 5N4, Canada

Tel + I 8198218000 ext 72912

Fax +I 8198206864

Email yannick.tousignant-laflamme@

usherbrooke.ca
Abstract: In the past, rehabilitation research initiatives for low back pain (LBP) have targeted outcome enhancement through personalized treatment approaches, namely through classification systems (CS). Although the use of CS has enhanced outcomes, common management practices have not changed, the prevalence of LBP is still high, and only selected patients meet the CS profile, namely those with a nociceptive context. Similarly, although practice guidelines propose some level of organization and occasionally a timeline of care provision, each mainly provides best practice for isolated treatment approaches. Moreover, there is no theoretical framework that has been proposed that guides the rehabilitation management process of mechanical LBP. In this commentary, we propose a model constituted of five domains (nociceptive drivers, nervous system dysfunction drivers, comorbidities drivers, cognitive-emotional drivers, and contextual drivers) grounded as mechanisms driving pain and/or disability in LBP. Each domain is linked to the International Classification of Functioning, Disability and Health, where once a patient is deemed suitable for rehabilitation, the clinician assesses elements of each domain in order to identify where the relative treatment efforts should be focused. This theoretical model is designed to provide a more comprehensive management overview, by appreciating the relative contribution of each domain driving pain and disability. Considering that the multiple domains driving pain and disability, and their interaction, requires a model that is comprehensive enough to identify and address each related issue, we consider that the proposed model has several positive implications for rehabilitation of this painful and highly prevalent musculoskeletal disorder. Keywords: low back pain, spine, rehabilitation, pain management

\section{Background}

Non-specific low back pain (LBP) is defined as "a symptom for which we are currently unable to reliably identify the pathology". ${ }^{1}$ This painful musculoskeletal problem is highly prevalent and recurrent in nature: the lifetime prevalence is estimated to be $84 \%$, and $\sim 55 \%$ of patients will have at least 10 episodes in their lifetime. ${ }^{2}$ With a point prevalence of $\sim 25 \%$, chronic LBP is a major health burden and is ranked as the most disabling pathology with respect to global burden of disease. ${ }^{3}$ In terms of disability adjusted life-years, LBP is the leading cause of years lived with disability in both developed and developing countries. ${ }^{3}$

Despite an intense focus and increased research funding, the self-reported levels of disability in individuals with LBP have not improved in the last decade. ${ }^{4}$ This situation prevails, notwithstanding the presence of multiple monodisciplinary classification tools designed to target patient-specific treatments, ${ }^{5,6}$ the presence of 15 international multidisciplinary guidelines for treatment of $\mathrm{LBP},{ }^{7}$ and the publication of numerous 
systematic reviews/meta-analyses on LBP. Each of these tools is designed to aid the clinical provider in identifying an optimal diagnosis and treatment approach, but it is likely that each has inherent limitations that fail to provide proper aid when dealing with the multidimensional complexities associated with LBP. For example, monodisciplinary (ie, physiotherapy) classification tools ${ }^{7-10}$ often focus on diagnosis and interventional measures solely for cases that involve pathoanatomical nociceptive presentations. Guidelines and systematic reviews/meta-analyses typically provide evidence for only discreet interventions. Clinical pathways of care, which are mainly derived from guidelines, might propose more comprehensive solutions to merge real-life clinical care with best practice. ${ }^{11}$ Recently, clinical care pathways have been proposed, ${ }^{11-13}$ yet their foci remain limited to the same specific biomechanical and psychological features found in LBP guidelines.

Studies have shown that factors involved in the development and chronification of LBP include psychological, biological, social, and environmental influences. ${ }^{8,9}$ These multidimensional mechanisms are well represented in the World Health Organization's International Classification of Functioning, Disability and Health (ICF) model. The ICF framework focuses on human functioning and provides a framework that captures how people with health conditions function in their daily life. It provides a scientific basis for understanding and studying health and health-related states and can also match patients to interventions. ${ }^{14}$

The health condition that constitutes LBP is characterized by impairments in body functions and structures (biological component) that can often lead to activity limitations or participation restrictions (functional component). The resulting LBP-related disability, which includes pain and activity limitations/participant restrictions, is also under the influence of personal and environmental factors. Thus, the ICF has a biopsychosocial framework that provides an overall view of the different aspects of health (biological, individual, and social); it could serve as the foundational underpinning of a comprehensive framework to better guide the rehabilitation management of LBP. Therefore, choosing the most appropriate assessment and treatment options through a construct that includes deficits in body functions and structures (ie, pain impairments) as well as full consideration of personal and environmental factors may provide additional benefits for the management of LBP. Accordingly, such model would implicitly take into account the biological components as well as the personal and environmental factors that might influence reports of pain and perceived or actual disability.
The objective of this conceptual paper is to propose an LBP management model that encompasses the multiple domains included within the ICF model. Our model does not propose a new classification system (CS), but intends to define the domains that drive the experience of pain and/or disability represented within the ICF.

\section{Part I: a management model based on factors driving pain and disability}

Our model proposes to establish the profile of patients based on the known drivers of disability - factors mechanistically driving pain and activity limitations/participation restrictions. To remain pragmatic, we propose a model constituted of five domains, which are all grounded into the known mechanisms driving the presence of painful symptoms and/or disability in LBP. Every element within each domain was included based on its relevance to the treatment decision making and prioritizing of the most pertinent interventions; in essence, to create a personalized rehabilitation management model. Conceptually, as proposed by other authors, ${ }^{15,16}$ once a patient is deemed appropriate for rehabilitation, the clinician should assess for the presence of elements attached to each of the five domains in order to identify which domain(s) might contribute to the clinical picture, and if "positive," on which particular elements relative treatment efforts should be focused. Consequently, this profiling would guide the management of mechanical LBP. As age (older age) has been shown to affect treatment outcomes, ${ }^{17}$ and most research upon which the proposed model is based on, elements included in the proposed model reflect care provided to an adult population.

\section{Domains and their operational definitions}

The five domains included in the proposed model are aligned alongside drivers of pain and/or disability. As pain is the most often reported deficit/impairment in LBP, it is first important to accurately appraise the relative importance of pain and its effect on function (disability) with adopted and recognized tools, as the ones proposed by the Initiative on Methods, Measurements and Pain Assessment in Clinical Trial (IMMPACT). The IMMPACT group has proposed specific assessment tools for core outcome domains in chronic pain, ${ }^{18}$ which have been adopted by many stakeholders.

As an attempt to quantify the relative contribution (severity) of each domain of interest, the domains we have included in our model contain two categories, the first (A) implicates more common and/or modifiable elements, whereas the second (B) involves elements that are more complex, less 
modifiable, and that will prompt more aggressive or require interdisciplinary care to more effectively address the problematic domain. Although these domains can interact and their relative individual contribution to pain and disability can modulate through time, the model gives a structure upon which the clinician can base its assessment (patient profiling) and consequently better target treatments, while reflecting a true biopsychosocial approach, as embraced by the ICF. The visual representation of the model is presented in Figure 1.

\section{Domain I - nociceptive pain drivers}

Nociceptive pain is "pain that arises from actual or threatened damage to non-neural tissue and is due to the activation of nociceptors". ${ }^{19}$ The presence of nociceptive pain relates to the
ICF as it is linked to deficits and impairments in body functions and structures. As the most frequent and primary driver of painful symptoms in cases of LBP result from the nociceptive system (somatic, inflammatory, or mixed pain), specific strategies to achieve pain control should initially target this driver of pain. This domain is composed of "responders to classification systems" (category A) and "non-responders to classification systems" (category B). Table 1 provides the operational definitions.

\section{Conceptual operationalization}

A two-step process can be used to determine whether a patient has predominantly nociceptive pain and driving his/ her LBP. The first step would be to confirm the presence of

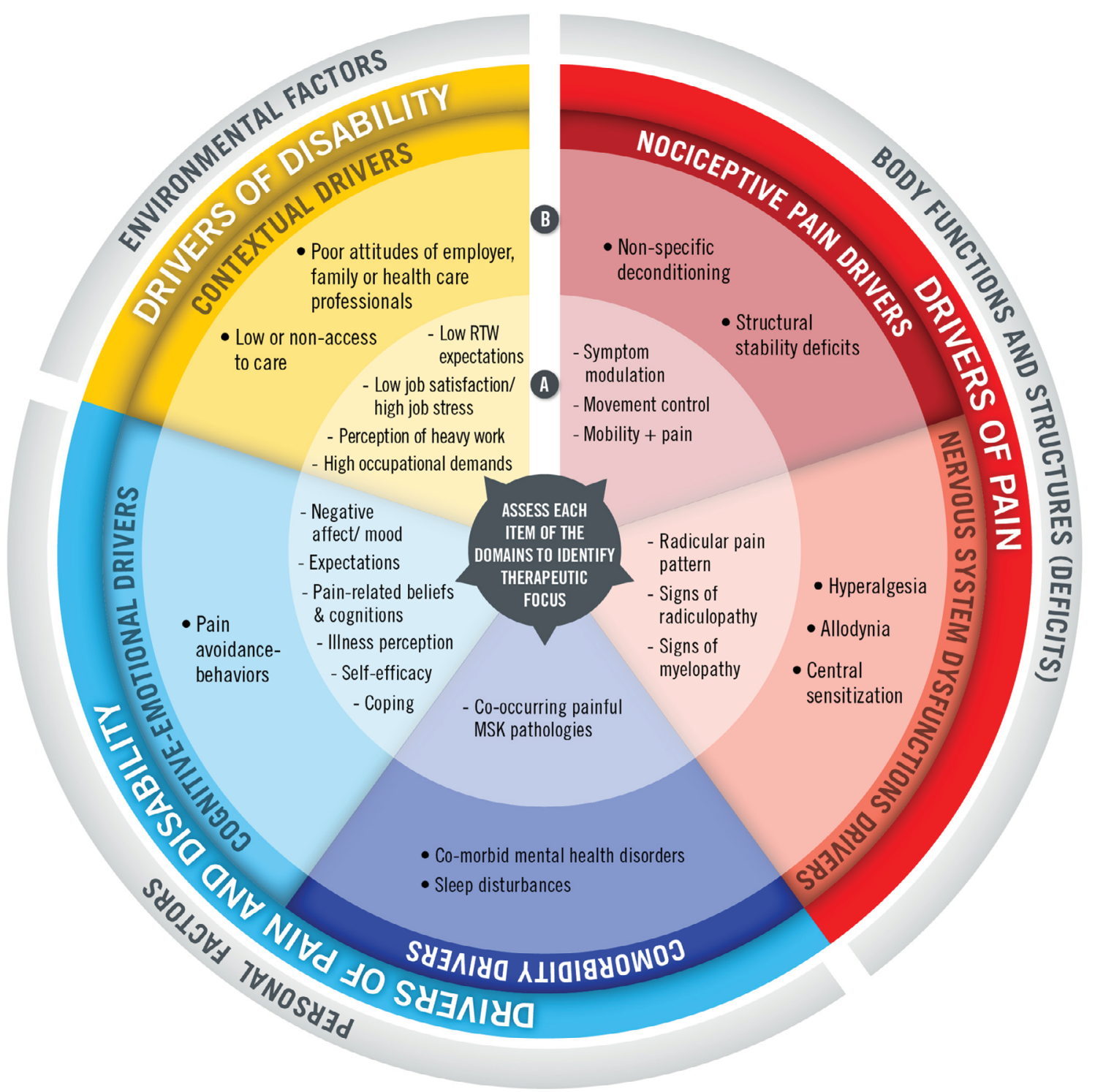

Figure I Pain and disability driver management model. (A) refers to more common and/or modifiable elements; (B) refers to elements that are more complex and less modifiable, and that will prompt more aggressive or require interdisciplinary care to effectively address the problematic domain.

Abbreviations: RTW, return to work; MSK, musculoskeletal. 
Table I Nociceptive pain drivers

\begin{tabular}{|c|c|c|}
\hline & Categories & Operational definition and elements of the category \\
\hline A & Responders to CS & $\begin{array}{l}\text { Elements in this category concern patients who have clinical characteristics of nociceptive pain, which } \\
\text { can be classified into a specific category of the current CS (ie, derangement category of the MDT). The } \\
\text { current CS can be broadly categorized into a symptom modulation approach (ie, MDT), movement } \\
\text { control approach (ie, MSI), or mobility and pain approach (ie, mobilizations). }{ }^{20-22} \\
\text { These patients could then be provided with matched treatment approach to address deficits in mobility } \\
\text { (ie, hypomobility as a cause of pain), movement control (ie, functional stability issues as cause of pain), } \\
\text { as well as symptom modulation approach, which implicates a specific mechanical pattern of pain (ie, } \\
\text { patients presenting the centralization phenomenon }{ }^{23} \text { ), hence will be prescribed specific exercises. Practice } \\
\text { guidelines do not suggest one particular CS over another, but the use of stratified care over non-stratified } \\
\text { management is advocated. }{ }^{24}\end{array}$ \\
\hline B & Non-responders to CS & $\begin{array}{l}\text { This category concerns patients who have clinical characteristics of nociceptive pain, but do not show } \\
\text { symptoms/signs allowing to be classified within one of the four main CS (non-responders). These patients } \\
\text { also present with nociceptive mechanical LBP and, as opposed to patients who fit into category A, are } \\
\text { likely to respond to non-specific exercises. }\end{array}$ \\
\hline
\end{tabular}

Abbreviations: CS, classification systems; LBP, low back pain; MDT, McKenzie Method ${ }^{\circledR}$ of Mechanical Diagnosis and Therapy ${ }^{\circledR}$ (MDT); MSI, Movement System Impairment Syndromes.

nociceptive pain with tools such as, but not limited to, the Pain Detect Questionnaire, a questionnaire that can be used as an objective diagnostic tool to distinguish nociceptive from neuropathic pain. ${ }^{25}$ The score indicates the likeliness of pain being nociceptive versus neuropathic. Once you have determined that there is a nociceptive component to the patient's symptoms, the patient should be assessed as recommended by practice guidelines ${ }^{26}$ using stratified care, ${ }^{24}$ which implies the use of a CS, such as the treatment-based CS. ${ }^{16}$ If you have determined that your patient meets the CS profile, then the patient should be provided with treatments matching their clinical characteristics and needs. The treatment approaches guided by CS, which mainly focus on deficits/impairments related to the biological aspects explaining the experience of pain, are fully capable of providing solutions addressing the nociceptive component of LBP.

If the patient has nociceptive pain but cannot be provided treatment guided by CS, hence a "non-responder," then the clinician should assess for other possible elements driving nociceptive pain. This would be the case for patients with post-surgical conditions (or structural stability deficits), which are likely to exhibit mechanical LBP, but without a specific mechanical pattern. Similar principles apply for highly deconditioned patients, where pain is likely to be nociceptive, but not associated with any specific mechanical pattern. Consequently, positive outcomes using CS guided by a movement-based classification or the functional optimization group of the treatment-based classification ${ }^{16}$ is less likely. Yet, these patients are likely to have somatic or inflammatory pain, both of which can be classified under nociceptive pain category, and it is anticipated that they will respond to general (non-specific) exercises, which will induce analgesia through specific analgesic mechanism. ${ }^{27}$ Thus, for the non-responders, the specificity of the exercises is less important.

Finally, we need to keep in mind that these treatment approaches mainly target nociceptive drivers of pain, and as explained earlier, disability is driven by multiple domains; hence, rehabilitation professionals will most likely need to look further. Considering that the sensory characteristics of pain in patients with LBP may be heterogeneous ${ }^{28}$ and that a continuum between nociceptive and neuropathic pain in LBP may exist, ${ }^{29}$ it may be relevant to explore other aspects of nervous system implications as drivers of pain.

\section{Domain 2 - nervous system dysfunction (NSD) drivers}

Whether a patient has nociceptive pain or not, it is relevant to explore if the nervous system itself (again linked to deficits/ impairments in body functions and structures) drives part of the painful symptoms. Since patients with neuropathic pain tend to have poorer outcomes, ${ }^{30}$ this information can enable the clinician to more effectively target the optimal treatment approach. For example, nociceptive mechanical LBP can also have concomitant neuropathic component, including but not limited to radicular pain. ${ }^{31}$ Furthermore, as recent progress in pain science has enhanced our understanding of pain science and the mechanisms involved in the maintenance of painful symptoms, there is now strong evidence suggesting that LBP can also be driven by sensitization of the peripheral and/or central nervous system. ${ }^{32}$

Hence, this domain relates to the nociception arising from dysfunction from the nervous system itself. ${ }^{29,33,34}$ These NSDs may take place at the peripheral, spinal, and even supra-spinal levels of the nervous system. ${ }^{35}$ This domain is composed of "peripheral or central sources of NSD" (category A) and 
"nervous system hypersensitivity" (category B). Table 2 provides the operational definitions.

\section{Conceptual operationalization}

Studies suggest that clinicians should specifically assess for the presence of NSD along with available information provided by CS and diagnostic procedures of LBP. ${ }^{38}$ Peripheral sources of NSD can readily be confirmed in clinical settings using the DN4. ${ }^{39}$ Distinguishing predominantly nociceptive LBP from neuropathic LBP can also be performed with the PainDETECT questionnaire, which has been shown to have significant sensibility/specificity to identify patients with a predominant neuropathic component to their LBP. ${ }^{25,40}$ As the first category (A) concerns signs and symptoms of peripheral NSD, clinicians should investigate for clinical signs and symptoms such as radicular pain pattern and symptoms, radiculopathy, and even low pain threshold (ie, proximal mechanical hyperalgesia), as they provide evidence of peripheral neural dysfunction. ${ }^{36}$ These elements can be measured in clinical settings by a simple neurological examination and/or algometry. Yet, it can remain challenging to distinguish from a truly peripheral versus a spinal/supra-spinal neuropathic component.

Thus, the second category (B), which implies characterization of pain-associated somatosensory changes, could serve to identify subgroups of patients with a predominant or enhanced nervous system excitability arising from the spinal or supra-spinal structures. As found by Smart et al, ${ }^{41}$ a clinical assessment/diagnosis of centrally mediated pain is feasible and is often seen as a continuum from peripheral nociceptive to peripheral and/or central neuropathic. ${ }^{42}$ More specifically, elements suggesting spinal/central nervous system hypersensitivity can include allodynia (ie, provoked by palpation) or reports of widespread body pain symptoms. Evidence of enhanced temporal summation of pain, which can be assessed using bedside quantitative sensory testing tools, is another indicator of central nervous system hypersensitivity (central sensitization) associated with chronic pain. ${ }^{43,44}$ Finally, the use of a questionnaire can also help document the presence of central sensitization - the Central Sensitization Inventory (CSI), which has sufficient validity to identify the presence of central sensitization ${ }^{45,46}$ in individuals with central sensitization syndromes.

When such elements characterize the patient's profile, the therapist must be able to adapt its treatment approach ${ }^{42,47}$ and add proper specific management strategies to the treatment plan. Furthermore, as the presence of NSD remains more complex to address, these patients are more likely to benefit from a parallel pharmacological approach. ${ }^{48}$ Yet, other domains may also drive the symptoms of pain and disability.

\section{Domain 3 - comorbidity drivers}

Besides their diagnosis of LBP, patients can also present with certain physical and/or mental health comorbidities that can influence other domains driving symptom severity and disability. In relation to the ICF, this third domain is part of the personal factors influencing pain and the resulting disability. For instance, it is not uncommon for people suffering from LBP to present with multiple painful musculoskeletal conditions ${ }^{49,50}$ - which tend to worsen the severity of symptoms of LBP. ${ }^{51}$ In addition to these comorbid physical problems, mental health comorbidities have also been found to be quite prevalent among patients with LBP. For instance, rates of depressive and anxiety disorders have been found to range between $20 \%$ and $50 \%$ among patients with chronic LBP. ${ }^{52,53}$ Personality disorders are also common psychiatric comorbidities observed among these patients. ${ }^{52}$ The presence of

Table 2 NSD drivers

\begin{tabular}{|c|c|c|}
\hline & Categories & Operational definition \\
\hline A & Peripheral or central NSDs & $\begin{array}{l}\text { Neuropathic pain is a type of pain caused by a lesion or disease of the somatosensory nervous system. } \\
\text { Hence, the peripheral nervous system can be a cause of pain associated with LBP. Clinical manifestations } \\
\text { of neuropathic pain associated with LBP have specific characteristics: paresthesia, tingling, burning, or } \\
\text { shooting pain. } \\
\text { Studies have shown that these pain characteristics and radicular pattern of pain (including radiculopathy) } \\
\text { provide evidence of peripheral NSD. }{ }^{36}\end{array}$ \\
\hline B & Nervous system hypersensitivity & $\begin{array}{l}\text { This category also involves NSD and concerns elements related to peripheral, spinal, or supra-spinal } \\
\text { hypersensitivity. This category conveys to more "serious" clinical manifestations such as evidence of } \\
\text { mechanosensitivity, hyperalgesia, allodynia, evidence of widespread pain location, or disproportional pain } \\
\text { intensity, which have been shown to be important indicators of spinal and supra-spinal hypersensitivity in } \\
\text { LBP patients. }{ }^{36,37} \text { In this context, nervous system hypersensitivity would be contributing factors driving the } \\
\text { painful symptoms. }\end{array}$ \\
\hline
\end{tabular}

Abbreviations: LBP, low back pain; NSD, nervous system dysfunction. 
elements within this second category clearly adds complexity to the clinical picture, as they certainly influence prognosis and treatment delivery. ${ }^{54}$ We have categorized those as physical comorbidities (A) and mental health comorbidities (B). Table 3 provides the operational definitions.

\section{Conceptual operationalization}

As the continuing presence of painful physical comorbidities and mental health comorbidities might influence other domains, such as nervous system hypersensitivity, and enhance pain, ${ }^{51}$ a thorough history and physical examination should be performed by the therapist to assess for their presence and relative implication in the patient's clinical profile. When significant painful musculoskeletal comorbidities are present, pain management strategies for concomitant (or paroxysmal) pain should be encompassed within the treatment plan for LBP. Furthermore, knowing that prolonged presence of painful pathologies is clearly linked to the presence/development of nervous system hypersensitivity, it is important that these should be screened/assessed and managed by the appropriately trained health care provider.

For their part, mental health comorbidities should be assessed with appropriate questions in the history or specific screening tools like the Beck Depression Inventory (BDI-II). ${ }^{62}$ If present, such comorbidities should also be targeted as part of the overall treatment plan of patients with LBP as depressive and anxiety disorders may prompt neuroplastic maladaptive changes in the central nervous system, ${ }^{59}$ which in turn may contribute to maintaining and/or amplifying the experience of pain. Hence, depression and anxiety may affect treatment strategies and modulate outcome expectations. ${ }^{63}$ Considering that patients presenting with depressive or anxiety disorders may require specific and targeted interventions, which go beyond psychologically informed physical rehabilitation interventions, therapists need to be prepared to seek medical interventions (or support from a mental health professional). In addition to influencing goal setting and expectations of improvements, these psychiatric comorbidities may directly or indirectly contribute to increasing pain perception ratings and perception of disability.

Furthermore, considering that chronic pain is associated with sleep disturbances, ${ }^{64}$ that LBP patients reporting sleep problems often report severe back pain, ${ }^{65-67}$ and that sleep deprivation triggers hyperalgesia, ${ }^{68}$ the presence of sleep disturbances should also be considered as a comorbidity potentially driving other domains, such as nervous system hypersensitivity. ${ }^{69}$

\section{Domain 4 - cognitive-emotional drivers}

As outlined by Borkum, ${ }^{70}$ maladaptive cognitions and maladaptive behaviors are part of personal factors influencing pain severity and disability. They are clearly linked to enhanced pain perception, are predictors of long-term disability, and can explain the presence of persistent painful symptoms. As personal factors of an individual, the fourth domain relates to cognitive-emotional drivers, as "maladaptive cognition" (category A) and "maladaptive behaviors" (category B) will undeniably influence the treatment approach. Table 4 provides the operational definitions.

\section{Conceptual operationalization}

Evidence-based practice strongly supports investigation of the presence of cognitive-emotional drivers of pain, using

Table 3 Comorbidity drivers

\begin{tabular}{|c|c|c|}
\hline & Categories & Operational definition \\
\hline A & Physical comorbidities & $\begin{array}{l}\text { Patients suffering from LBP often present with multiple painful musculoskeletal conditions }{ }^{49,50} \text { and other } \\
\text { physical comorbidities. Studies have shown that these other painful problems tend to worsen the severity of } \\
\text { symptoms of LBP. }{ }^{51} \text { Also, the presence of specific co-occurring pathologies, such as chronic fatigue, irritable } \\
\text { bowel syndrome, and migraines could moderate the "nervous system dysfunction drivers" as they are linked to } \\
\text { central sensitization. } \\
\text { Other non-painful physical comorbidities, such as cardiac disease }{ }^{55} \text { and high BMI, }{ }^{56-58} \text { are also associated with } \\
\text { chronic LBP, but their treatment implications are less certain. Although some elements might be harder to } \\
\text { modify by short-term treatments (ie, high BMI), these could serve as motivational elements to help enhance } \\
\text { patient engagement. }\end{array}$ \\
\hline B & Mental health comorbidities & $\begin{array}{l}\text { This category involves disorders of the standard classification of mental disorders, the Diagnostic and Statistical } \\
\text { Manual of Mental Disorders (DSM-5). Clinical depression is an important factor since pain and depression share } \\
\text { some biological processes }{ }^{59} \text { and both prompt neuroplastic maladaptive changes in the central nervous system. }{ }^{59} \\
\text { Besides depression, the presence of other mental disorders or psychiatric comorbidity such as general anxiety } \\
\text { disorder }{ }^{60} \text { or borderline personality disorder }{ }^{61} \text { are important treatment modifiers, as they certainly challenge } \\
\text { the therapist's approach for the management of LBP and further moderate the effects of cognitive-emotional } \\
\text { drivers. }\end{array}$ \\
\hline
\end{tabular}

Abbreviations: LBP, low back pain; BMI, body mass index. 
Table 4 Cognitive-emotional drivers

\begin{tabular}{|c|c|c|}
\hline & Categories & Operational definition and elements \\
\hline A & Maladaptive cognition & $\begin{array}{l}\text { Cognitive-emotional drivers include maladaptive cognitive strategies toward pain (ie, pain coping, pain } \\
\text { catastrophizing), pain-related fears (ie, pain-related anxiety and fear, fear of movement), negative perception of } \\
\text { pain/disability and expectations toward pain (ie, illness perception, pain self-efficacy), as well as negative mood } \\
\text { (which is distinct from clinical depression). According to the fear-avoidance model, }{ }^{71} \text { when maladaptive cognitive } \\
\text { drivers are not addressed and if pain/disability persists, factors such catastrophizing, illness perceptions, negative } \\
\text { emotions, and pain-related fears may lead to the development of maladaptive behaviors (eg, activity avoidance), } \\
\text { which, in turn, may contribute to the maintenance of pain-related disability. }{ }^{72}\end{array}$ \\
\hline B & Maladaptive behaviors & $\begin{array}{l}\text { Maladaptive behaviors can be manifested in various ways. For example, they may include "communicative" pain } \\
\text { behaviors such as facial expressions (eg, grimacing or wincing) or verbal/paraverbal pain expressions (eg, pain } \\
\text { words, grunts, sighs, and moans). They may also include "protective" or "safety" behaviors such as guarding of the } \\
\text { back straight while lifting or bending/rubbing the back after performing an activity, strongly bracing before doing a } \\
\text { functional task, or even completely avoiding performing a task. }{ }^{73} \\
\text { In addition to avoidance, displays of "protective/safety" behaviors (eg, guarding, holding, or rubbing the back) } \\
\text { or communicative pain behaviors (eg, grimaces) have also been associated with heightened levels of perceived } \\
\text { functional disability. }{ }^{74,75} \text { Maladaptive behaviors are known to be strongly influenced by cognitive-emotional } \\
\text { factors; }{ }^{75-77} \text { their presence suggests that cognitive-emotional drivers of pain must be assessed and addressed } \\
\text { through behavioral or cognitive-behavioral treatment interventions. }{ }^{79}\end{array}$ \\
\hline
\end{tabular}

screening tools such as the StartBack questionnaire. ${ }^{80}$ If a patient is categorized into a medium- to high-risk category, psychological interventions as part of the rehabilitation plan are likely to be beneficial. Consequently, for patients at risk, the clinician could also investigate for the presence of other specific maladaptive cognitions, such as fear avoidance, pain catastrophizing, poor coping, and low self-efficacy, as they are known to be potentially modifiable through rehabilitation and psychologically informed PT interventions ${ }^{81}$ Clinical studies have shown that when these elements are targeted through a psychologically informed treatment approach, positive outcomes in pain and function are often observable. ${ }^{82,83}$ This reflects on the importance of the integration of adequate profiling and management strategies in addition to the other contributing domains previously identified. Furthermore, research has also shown that when treatment effects are limited, multidimensional interventions (beyond psychologically informed care) are more effective to address these challenges associated with LBP. ${ }^{84}$

Given that maladaptive behaviors have been found to persist over time, independent of cognitive-emotional drivers, ${ }^{85}$ these should also be directly targeted and reduced over the course of treatment. To date, outside of direct observation, we are poorly equipped to objectively measure maladaptive behaviors. Clinicians have traditionally relied on methods such as the Waddell's non-organic signs, a screening test that can alert the clinician that a patient needs care oriented to address illness behaviors. ${ }^{86}$ Over the years, behavioral observation methods have been developed to assess and rapidly quantify maladaptive pain behaviors among LBP patients. ${ }^{87,88}$ More recently, the Behavioral Avoidance Test for back pain (BAT-Back) ${ }^{73}$ has been developed to assess pain-related avoidance behaviors by direct observations and could serve as a more comprehensive tool to establish the patient's profile. Moreover, as pain behaviors can also be influenced by social elements, ${ }^{85}$ environmental factors must also be taken into account.

\section{Domain 5 - contextual drivers}

As we have previously described, the social component of the biopsychosocial model is the weakest component of all current CSs for LBP and is scarcely mentioned in practice guidelines, as the latter mainly target nociceptive sources of pain and disability. Yet, like personal factors, environmental factors may have a significant influence on outcomes. ${ }^{89}$ Not surprisingly, there is a considerable quantity of literature supporting the influence of these contextual factors on painful symptoms and more importantly work-related disability. We have organized this fifth domain into two categories: (A) occupation-related contextual drivers and (B) social environment contextual drivers. Table 5 provides the operational definitions.

\section{Conceptual operationalization}

When a patient presents with disability, clinicians need to explore the influence of contextual elements related to the patient's occupation (work) and social context (ie, family) on the patient's painful symptoms and disability. ${ }^{90}$ With a working adult population, assessing the presence of contextual factors that affect work disability is crucial as it will guide treatment. Beside a comprehensive interview, when the patient is not yet chronic ( $<6$ months), clinicians can 
Table 5 Contextual drivers

\begin{tabular}{|c|c|c|}
\hline & Categories & Operational definition and elements \\
\hline$A$ & $\begin{array}{l}\text { Occupation-related contextual } \\
\text { drivers }\end{array}$ & $\begin{array}{l}\text { Elements of this category relate to the patient's perception or beliefs as well as factual elements in regard } \\
\text { to the patient's work/occupation environment. Some elements are to some extent modifiable by the } \\
\text { therapist's approach. These include expectations about return to work, job satisfaction, perception of heavy } \\
\text { work, and high job stress. When negative perception about work is identified throughout the interview, } \\
\text { these will need to be addressed within your therapeutic strategy. Furthermore, other factual elements } \\
\text { might also influence your treatment approach. Much less modifiable by therapy, they include occupational } \\
\text { demands (ie, sedentary versus heavy work), job flexibility (ie, availability of modified work), employer's } \\
\text { policies regarding return to work (which can be distinct from provincial/state laws). These will greatly } \\
\text { dictate the framework the therapist will have to work with }{ }^{90} \text { and command communication with the } \\
\text { employer and/or other health care providers }\end{array}$ \\
\hline B & $\begin{array}{l}\text { Social environment contextual } \\
\text { drivers }\end{array}$ & $\begin{array}{l}\text { As social support from the patient's environment is an important predictor of success, }{ }^{91} \text { this second } \\
\text { category relates to contextual elements in the patient's social environment. Elements in this category are } \\
\text { mostly related to attitudes of the persons within the patient's environment, including but not limited to } \\
\text { employer, family members, and health care professionals. Access to care (ie, limited access to rehabilitation) } \\
\text { would also be a contextual element that can drive part of the patient's disability. }\end{array}$ \\
\hline
\end{tabular}

use the Orebro musculoskeletal pain screening questionnaire. ${ }^{92,93}$ Similar to the StartBack tool, it has been developed to predict who is likely to remain on prolonged sick leave. However, when a patient has persistent pain and is disabled from work, therapists need to explore the specific influence of workplace and social context on the patient's disability. ${ }^{90}$ Hence, some elements of the first category are related to the patient's subjective beliefs about work, as the patient's attitude toward his/her job is a strong predictor of disability and pain. ${ }^{94-96}$ Considering that certain elements are to some extent modifiable, when negative perceptions about work are identified throughout the interview, these will need to be addressed and part of one's treatment strategy. Yet, some contextual elements in regard to the patient's occupation might also be non-modifiable (ie, employer's policies regarding return to work). Nonetheless, these non-modifiable elements are important to assess as they will provide a "framework" for the therapist and the patient to work within.

Although the interview remains the main way to gather information about the relative contribution/presence of occupation-related elements, a very recent scoping review found interesting tools. ${ }^{97}$ Among others, the Work Assessment Triage Tool ${ }^{98}$ captures 18 variables related to injury duration, job, working status, and availability of modified work. According to the patient/therapist response, it suggests best work reintegration options. Although in its early stage of validation, ${ }^{97}$ the Work Assessment Triage Tool yielded greater probability to recommend evidence-based multi/ inter-disciplinary approaches than clinicians' opinions.

As for the second category, which concerns contextual elements part of the patient's social environment, it is important for the therapist to assess the past or current elements that could shape the intervention. For example, attitudes of employers, family members, and even current or past health care professionals may influence the therapeutic alliance, an important non-specific approach that enhances clinical outcomes. ${ }^{99}$ Furthermore, if interdisciplinary interventions are required and the patients do not have access to this type of care, this practice will shape the way the clinician can deliver its interventions; rehabilitation professionals need to stay within their scope of practice, but might have to go beyond their usual treatment strategies to properly address the problematic elements of this domain.

\section{Part 2: practical integration of the model into practice}

Once a patient is deemed suitable for rehabilitation (ie, no red flags), our model proposes a structure to further guide the clinician's assessment. In essence, rehabilitation professionals should establish the patient's profile based on the presence/absence of elements within each domain - this would then identify and target where the relative treatment efforts should be focused. Accordingly, this theoretical model is designed to provide a more comprehensive management overview, by appreciating the relative contribution of each domain driving pain and disability. The following clinical profiles of two hypothetical case examples illustrates this.

Patient A presents with painful symptoms in the low back area along with left leg pain that he describes as dull and achy. The pain is considered to mainly be nociceptive. He shows centralization of his symptoms after repeated lumbar extension exercises, but also has signs of radiculopathy (decreased endurance of dorsiflexors) related to his leg pain. At 5' $8^{\prime \prime}$ and $245 \mathrm{lbs}$, he is aware that his extra weight probably does 
not help his condition and that his co-occurring history of severe bilateral knee osteoarthritis pain does not help either. He reports that his mood is good, but he scores $6 / 9$ on the StartBack questionnaire and does not see the day when he will be ready to return to work, although his employer is already willing to accommodate him.

Patient B presents with pain located in the low back as well as the posterior aspect of both thighs that he describes as lancinating - the painDetect questionnaire points to a neuropathic component. The segmental hypomobility observed in the lower segments of the lumbar spine during the physical examination does not change his symptoms. He has full range of motion and repeated movement examination does not reveal any specific mechanical pattern of pain (no directional preference either). However, he is also complaining of intermittent pain in his upper back and neck along with sleep disturbances, as pain wakes him up 5-6 times per night. He scores 42 on the CSI questionnaire, where questions regarding fatigue and endurance scored highest. He has concomitant physical comorbidity (migraines) but no mental health comorbidities. He clearly shows pain behaviors in the clinic (grimaces, guarding) and scores $8 / 9$ on the StartBack tool. During the initial assessment, the therapist notes poor perception regarding return to work and high occupational demands for this 49-year-old welder.

After assessing for the presence of elements within each of the five domains, a profile can emerge highlighting which domain(s) drive the patient's painful symptoms and/ or disability. As Figure 2 illustrates, we have plotted the hypothetical relative contribution of each domain for both cases (note that future studies would help us to determine how each parameter would be weighted). As a result, we can speculate that treatment approach should mainly focus on nociceptive pain drivers for patient $\mathrm{A}$, where the integration of specific exercises will take a greater importance in the patient's treatment plan. On the opposite, therapeutic efforts should be focused on NSDs and cognitive-emotional drivers for patient $B$.

Could the use of this model/structure help the clinician to better target care? Could it enhance management by appropriately focusing interventions on the most important drivers of disability? Future research will answer these questions, but the use of the Pain and Disability Drivers Management model offers a comprehensive structure to the clinician, which goes beyond traditional routes proposed by stratified care approaches and has numerous potential advantages.

\section{Part 3: potential advantages of this integrative model and implications for rehabilitation}

Based on the ICF framework, a truly biopsychosocial model, the mechanistically driven model we proposed reflects the multiple components of factors driving disability in LBP. It has the potential to allow the therapist to appreciate the relative contribution of each domain influencing the patient's experience, while providing clinicians with a structured assessment and specific targets on which to focus their treatment approach. For the two main domains driving pain (nociceptive drivers and nervous system dysfunction drivers), our position goes beyond the traditional "biomechanical" classifications with the integration of a domain relating to nervous system dysfunc-

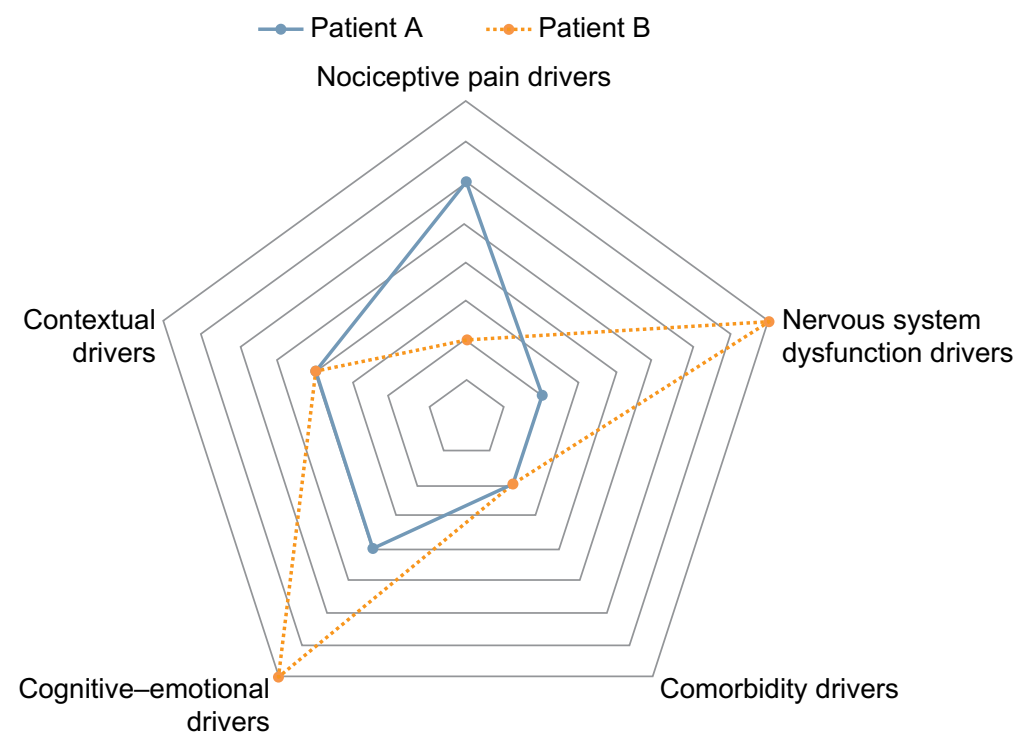

Figure 2 Treatment guidance capacity/potential of the pain and disability drivers management model. 
tions. This provides a more inclusive and holistic perspective of the neurophysiological components of pain; NSD covers different underlying mechanisms, typically inadequately integrated by the four main CS. ${ }^{21}$ This addition can help to distinguish patients with LBP presenting with mechanical and non-mechanical aggravating factors and better reflects the diversity of clinical manifestations observed in LBP, an important aspect previously proposed by Scholz et al. ${ }^{100}$

Currently, a mismatch probably exists between the different types of treatments provided to patients with LBP and the "true" underlying mechanisms. ${ }^{101,102}$ Since management of LBP based exclusively on deficits in body functions and structures (biomechanical approach) renders sub-optimal outcomes, our model urges for the integration of targeted intervention in regard to domains related to personal and environmental factors. Recently, Rabey et al stated that "a flexible, biopsychosocial classification system may allow profiling across multiple relevant dimensions, to facilitate targeted care based on the dominant factors present in individual profiles". ${ }^{22}$ Previous authors have urged for a more contemporary vision of LBP management while focusing on the relative importance of multidimensional profiling. ${ }^{103}$ With respect to these comments, we consider that our model is client-centered, multidimensional, and most importantly, gives to the clinician a structure to better target the multiple dimensions associated with LBP, while remaining relatively simple. Although a more comprehensive biopsychosocial profiling of patients with LBP has recently been explored, ${ }^{104}$ it remains challenging to clinically interpret results from cluster analysis and to translate these findings into clinical practice.

\section{Conclusion}

Based on the need for a more organized and targeted health care delivery ${ }^{13}$ and the need for a cultural shift in the management of LBP, ${ }^{103}$ this model has the capability to help the clinician recognize if and when multidisciplinary care is needed and provide a roadmap that puts into context the complexity of recovery in this heterogeneous population. This theoretical model could provide better structure and certainly a more comprehensive one than the current CS. ${ }^{105}$ Although the relative importance of each domain incorporated in our model may (and will) vary on a chronological basis and interact with other domains, our model could help the clinicians to provide the most comprehensive and appropriate care to their patients.

\section{Disclosure}

Yannick Tousignant-Laflamme is a supported member of the Clinical Research Center of the Centre Hospitalier Universitaire de Sherbrooke. Marc Olivier Martel and Yannick
Tousignant-Laflamme are both members of the Quebec Pain Research Network (QPRN). The authors report no other conflicts of interest in this work.

\section{References}

1. Balague F, Mannion AF, Pellise F, Cedraschi C. Non-specific low back pain. Lancet. 2012;379(9814):482-491.

2. Donelson R, McIntosh G, Hall H. Is it time to rethink the typical course of low back pain? PM R. 2012;4(6):394-401; quiz 400.

3. Hoy D, March L, Brooks P, et al. The global burden of low back pain: estimates from the Global Burden of Disease 2010 study. Ann Rheum Dis. 2014;73(6):968-974.

4. GBD 2015 Disease and Injury Incidence and Prevalence Collaborators. Global, regional, and national incidence, prevalence, and years lived with disability for 310 diseases and injuries, 1990-2015: a systematic analysis for the Global Burden of Disease Study 2015. Lancet. 2016;388(10053):1545-1602.

5. Fritz JM, Delitto A, Erhard RE. Comparison of classification-based physical therapy with therapy based on clinical practice guidelines for patients with acute low back pain: a randomized clinical trial. Spine (Phila Pa 1976). 2003;28(13):1363-1371; discussion 1372.

6. Mafi JN, McCarthy EP, Davis RB, Landon BE. Worsening trends in the management and treatment of back pain. JAMA Intern Med. 2013;173(17):1573-1581.

7. Koes BW, van Tulder M, Lin CW, Macedo LG, McAuley J, Maher C. An updated overview of clinical guidelines for the management of non-specific low back pain in primary care. Eur Spine J. 2010;19(12): 2075-2094.

8. Taylor JB, Goode AP, George SZ, Cook CE. Incidence and risk factors for first-time incident low back pain: a systematic review and metaanalysis. Spine J. 2014;14(10):2299-2319.

9. Chou R, Shekelle P. Will this patient develop persistent disabling low back pain? JAMA. 2010;303(13):1295-1302.

10. Manchikanti L, Benyamin RM, Helm S, Hirsch JA. Evidence-based medicine, systematic reviews, and guidelines in interventional pain management: part 3: systematic reviews and meta-analyses of randomized trials. Pain Physician. 2009;12(1):35-72.

11. Fourney DR, Dettori JR, Hall H, Härtl R, McGirt MJ, Daubs MD. A systematic review of clinical pathways for lower back pain and introduction of the Saskatchewan Spine Pathway. Spine (Phila Pa 1976). 2011;36(21 Suppl):S164-S171.

12. Lee J, Gupta S, Price C, Baranowski AP; British Pain Society. Low back and radicular pain: a pathway for care developed by the British Pain Society. Br J Anaesth. 2013;111(1):112-120.

13. Maiers MJ, Westrom KK, Legendre CG, Bronfort G. Integrative care for the management of low back pain: use of a clinical care pathway. BMC Health Serv Res. 2010;10(1):298.

14. Escorpizo R. Defining the principles of musculoskeletal disability and rehabilitation. Best Pract Res Clin Rheumatol. 2014;28(3):367-375.

15. Abbott A. Evidence base and future research directions in the management of low back pain. World J Orthop. 2016;7(3):156-161.

16. Alrwaily M, Timko M, Schneider M, et al. Treatment-based classification system for low back pain: revision and update. Phys Ther. 2016;96(7):1057 LP-1066 LP.

17. Garcia AN, Costa L da CM, Hancock M, Costa LOP. Identifying patients with chronic low back pain who respond best to mechanical diagnosis and therapy: secondary analysis of a randomized controlled trial. Phys Ther. 2016;96(5):623-630.

18. Dworkin RH, Turk DC, Farrar JT, et al. Core outcome measures for chronic pain clinical trials: IMMPACT recommendations. Pain. 2005;113(1-2):9-19.

19. IASP Taxonomy - IASP. Available from: http://www.iasp-pain.org/ Taxonomy\#Nociceptivepain. Accessed February 6, 2017.

20. Karayannis N V, Jull GA, Hodges PW. Movement-based subgrouping in low back pain: synergy and divergence in approaches. Physiotherapy. 2015;102(2):159-169. 
21. Karayannis NV, Jull GA, Hodges PW. Physiotherapy movement based classification approaches to low back pain: comparison of subgroups through review and developer/expert survey. BMC Musculoskelet Disord. 2012;13:24.

22. Rabey M, Beales D, Slater H, O'Sullivan P. Multidimensional pain profiles in four cases of chronic non-specific axial low back pain: an examination of the limitations of contemporary classification systems. Man Ther. 2015;20(1):138-147.

23. Long AL. The centralization phenomenon. Its usefulness as a predictor or outcome in conservative treatment of chronic law back pain (a pilot study). Spine (Phila Pa 1976). 1995;20(23):2513-20; discussion 2521.

24. Foster NE, Hill JC, O'Sullivan P, Hancock M. Stratified models of care. Best Pract Res Clin Rheumatol. 2013;27(5):649-661.

25. Spahr N, Hodkinson D, Jolly K, Williams S, Howard M, Thacker M. Distinguishing between nociceptive and neuropathic components in chronic low back pain using behavioural evaluation and sensory examination. Musculoskelet Sci Pract. 2017;27:40-48.

26. Delitto A, George SZ, Van Dillen LR, et al. Low back pain. J Orthop Sports Phys Ther. 2012;42(4):A1-A57.

27. Koltyn KF, Brellenthin AG, Cook DB, Sehgal N, Hillard C. Mechanisms of exercise-induced hypoalgesia. J Pain. 2014;15(12):1294-1304.

28. Rabey M, Slater H, O'Sullivan P, Beales D, Smith A. Somatosensory nociceptive characteristics differentiate subgroups in people with chronic low back pain. Pain. 2015;156(10):1874-1884.

29. Smart KM, Blake C, Staines A, Thacker M, Doody C. Mechanismsbased classifications of musculoskeletal pain: part 1 of 3: symptoms and signs of central sensitisation in patients with low back ( \pm leg) pain. Man Ther. 2012;17(4):336-344.

30. Smith BH, Torrance N, Bennett MI, Lee AJ. Health and quality of life associated with chronic pain of predominantly neuropathic origin in the community. Clin J Pain. 2007;23(2):143-149.

31. Bogduk N. On the definitions and physiology of back pain, referred pain, and radicular pain. Pain. 2009;147(1):17-19.

32. Woolf CJ. Central sensitization: implications for the diagnosis and treatment of pain. Pain. 2011;152(3 Suppl):S2-S15.

33. Smart KM, Blake C, Staines A, Thacker M, Doody C. Mechanismsbased classifications of musculoskeletal pain: part 2 of 3: Symptoms and signs of peripheral neuropathic pain in patients with low back $( \pm$ leg) pain. Man Ther. 2012;17(4):345-351.

34. Smart KM, Blake C, Staines A, Thacker M, Doody C. Mechanismsbased classifications of musculoskeletal pain: part 3 of 3: symptoms and signs of nociceptive pain in patients with low back ( \pm leg) pain. Man Ther. 2012;17(4):352-357.

35. Blond S, Mertens P, David R, Roulaud M, Rigoard P. From "mechanical" to "neuropathic" back pain concept in FBSS patients. A systematic review based on factors leading to the chronification of pain (part C). Neurochirurgie. 2015;61:S45-S56.

36. Starkweather AR, Ramesh D, Lyon DE, et al. Acute low back pain: differential somatosensory function and gene expression compared with healthy no-pain controls. Clin J Pain. 2016;32(11):933-939.

37. Corrêa JB, Costa LOP, de Oliveira NTB, Sluka KA, Liebano RE. Central sensitization and changes in conditioned pain modulation in people with chronic nonspecific low back pain: a case-control study. Exp Brain Res. 2015;233(8):2391-2399.

38. Nijs J, Apeldoorn A, Hallegraeff H, et al. Low back pain: guidelines for the clinical classification of predominant neuropathic, nociceptive, or central sensitization pain. Pain Physician. 2015;18(3):E333-E346.

39. Attal N, Perrot S, Fermanian J, Bouhassira D. The neuropathic components of chronic low back pain: a prospective multicenter study using the DN4 questionnaire. J Pain. 2011;12(10):1080-1087.

40. Freynhagen R, Baron R, Gockel U, Tölle TR. painDETECT: a new screening questionnaire to identify neuropathic components in patients with back pain. Curr Med Res Opin. 2006;22(10):1911-1920.

41. Smart KM, Blake C, Staines A, et al. Clinical indicators of "nociceptive", "peripheral neuropathic" and "central" mechanisms of musculoskeletal pain. A Delphi survey of expert clinicians. Man Ther 2010;15(1):80-87.
42. Nijs J, Torres-Cueco R, van Wilgen CP, et al. Applying modern pain neuroscience in clinical practice: criteria for the classification of central sensitization pain. Pain Physician. 2014;17(5):447-457.

43. Graven-Nielsen T, Arendt-Nielsen L. Assessment of mechanisms in localized and widespread musculoskeletal pain. Nat Rev Rheumatol. 2010;6(10):599-606.

44. Staud R. The important role of CNS facilitation and inhibition for chronic pain. Int J Clin Rheumtol. 2013;8(6):639-646.

45. Neblett R, Hartzell MM, Cohen H, et al. Ability of the central sensitization inventory to identify central sensitivity syndromes in an outpatient chronic pain sample. Clin J Pain. 2015;31(4):323-332.

46. Neblett R, Hartzell MM, Mayer TG, Cohen H, Gatchel RJ. Establishing clinically relevant severity levels for the central sensitization inventory. Pain Pract. 2017;17(2):166-175.

47. Clauw DJ. Diagnosing and treating chronic musculoskeletal pain based on the underlying mechanism(s). Best Pract Res Clin Rheumatol. 2015;29(1):6-19.

48. Moskowitz MH. Pharmacotherapy of neuropathic low back pain. Curr Pain Headache Rep. 2003;7(3):178-187.

49. Ramond-Roquin A, Pecquenard F, Schers H, Van Weel C, Oskam S, Van Boven K. Psychosocial, musculoskeletal and somatoform comorbidity in patients with chronic low back pain: original results from the Dutch Transition Project. Fam Pract. 2015;32(3):297-304.

50. Gore M, Sadosky A, Stacey BR, Tai K-S, Leslie D. The burden of chronic low back pain. Spine (Phila Pa 1976). 2012;37(11):E668-E677.

51. Hartvigsen J, Natvig B, Ferreira M. Is it all about a pain in the back? Best Pract Res Clin Rheumatol. 2013;27(5):613-623.

52. Dersh J, Gatchel RJ, Mayer T, Polatin P, Temple OR. Prevalence of psychiatric disorders in patients with chronic disabling occupational spinal disorders. Spine (Phila Pa 1976). 2006;31(10):1156-1162.

53. Katz J, Rosenbloom BN, Fashler S. Chronic pain, psychopathology, and DSM-5 somatic symptom disorder. Can J Psychiatry. 2015;60(4):160-167.

54. Wasan AD, Michna E, Edwards RR, et al. Psychiatric comorbidity is associated prospectively with diminished opioid analgesia and increased opioid misuse in patients with chronic low back pain. Anesthesiology. 2015;123(4):861-872.

55. Fayaz A, Watt HC, Langford RM, Donaldson LJ. The Association Between Chronic Pain and Cardiac Disease. Clin J Pain. 2016;32(12):1062-1068.

56. Heuch I, Heuch I, Hagen K, Zwart J-A. Body Mass Index as a Risk Factor for Developing Chronic Low Back Pain. Spine (Phila Pa 1976). 2013;38(2):133-139.

57. Häuser W, Schmutzer G, Brähler E, Schiltenwolf M, Hilbert A. The Impact of Body Weight and Depression on Low Back Pain in a Representative Population Sample. Pain Med. 2014;15(8):1316-1327.

58. Urquhart DM, Berry P, Wluka AE, et al. 2011 Young Investigator Award Winner. Spine (Phila Pa 1976). 2011;36(16):1320-1325.

59. Doan L, Manders T, Wang J. Neuroplasticity underlying the comorbidity of pain and depression. Neural Plast. 2015;2015:1-16.

60. Kayhan F, Albayrak Gezer İ, Kayhan A, Kitiş S, Gölen M. Mood and anxiety disorders in patients with chronic low back and neck pain caused by disc herniation. Int J Psychiatry Clin Pract. 2016;20(1):19-23.

61. Sansone RA, Sansone LA. Chronic pain syndromes and borderline personality. Innov Clin Neurosci. 2012;9(1):10-14.

62. Harris CA, D’Eon JL. Psychometric properties of the Beck Depression Inventory - second edition (BDI-II) in individuals with chronic pain. Pain. 2008;137(3):609-622.

63. Bair MJ, Robinson RL, Katon W, Kroenke K. Depression and pain comorbidity: a literature review. Arch Intern Med. 2003;163(20):2433-2445.

64. Marin R, Cyhan T, Miklos W. Sleep disturbance in patients with chronic low back pain. Am J Phys Med Rehabil. 2006;85(5):430-435.

65. Lusa S, Miranda H, Luukkonen R, Punakallio A. Sleep disturbances predict long-term changes in low back pain among Finnish firefighters: 13-year follow-up study. Int Arch Occup Environ Health. 2015;88(3): 369-379. 
66. Alsaadi SM, McAuley JH, Hush JM, et al. The bidirectional relationship between pain intensity and sleep disturbance/quality in patients with low back pain. Clin J Pain. 2014;30(9):755-765.

67. Alsaadi SM, McAuley JH, Hush JM, et al. Poor sleep quality is strongly associated with subsequent pain intensity in patients with acute low back pain. Arthritis Rheumatol. 2014;66(5):1388-1394.

68. Schuh-Hofer S, Wodarski R, Pfau DB, et al. One night of total sleep deprivation promotes a state of generalized hyperalgesia: A surrogate pain model to study the relationship of insomnia and pain. Pain. 2013;154(9):1613-1621.

69. Nijs J, Goubert D, Ickmans K. Recognition and treatment of central sensitization in chronic pain patients: not limited to specialized care. J Orthop Sport Phys Ther. 2016;46(12):1024-1028.

70. Borkum JM. Maladaptive cognitions and chronic pain: epidemiology, neurobiology, and treatment. J Ration Cogn Ther. 2010;28(1):4-24.

71. Vlaeyen JWS, Linton SJ. Fear-avoidance model of chronic musculoskeletal pain: 12 years on. Pain. 2012;153(6):1144-1147.

72. Boersma K, Linton SJ. How does persistent pain develop? An analysis of the relationship between psychological variables, pain and function across stages of chronicity. Behav Res Ther. 2005;43(11):1495-1507.

73. Holzapfel S, Riecke J, Rief W, Schneider J, Glombiewski JA. Development and Validation of the Behavioral Avoidance Test-Back Pain (BAT-Back) for Patients With Chronic Low Back Pain. Clin J Pain. 2016;32(11):940-947.

74. Prkachin KM, Schultz IZ, Hughes E. Pain behavior and the development of pain-related disability: the importance of guarding. Clin $J$ Pain. 2007;23(3):270-277.

75. Thibault P, Loisel P, Durand MJ, Catchlove R, Sullivan MJL. Psychological predictors of pain expression and activity intolerance in chronic pain patients. Pain. 2008;139(1):47-54.

76. Keefe FJ, Wilkins RH, Cook Jr. WA, Crisson JE, Muhlbaier LH. Depression, Pain, and Pain Behavior. J Consult Clin Psychol. 1986;54(5):665-669.

77. Sullivan MJL, Rodgers WM, Wilson PM, Bell GJ, Murray TC, Fraser $\mathrm{SN}$. An experimental investigation of the relation between catastrophizing and activity intolerance. Pain. 2002;100(1-2):47-53.

78. Brunner E, De Herdt A, Minguet P, Baldew SS, Probst M. Can cognitive behavioural therapy based strategies be integrated into physiotherapy for the prevention of chronic low back pain? A systematic review. Disabil Rehabil. 2013;35(1):1-10.

79. Keogh A, Tully MA, Matthews J, Hurley DA. A review of behaviour change theories and techniques used in group based self-management programmes for chronic low back pain and arthritis. Man Ther. 2015;20(6):727-735.

80. Beneciuk JM, Bishop MD, Fritz JM, et al. The STarT back screening tool and individual psychological measures: evaluation of prognostic capabilities for low back pain clinical outcomes in outpatient physical therapy settings. Phys Ther. 2013;93(3):321-333.

81. Gatchel RJ, Neblett R, Kishino N, Ray CT. Fear-avoidance beliefs and chronic pain. J Orthop Sport Phys Ther. 2016;46(2):38-43.

82. Foster NE, DeLitto A. Embedding psychosocial perspectives within clinical management of low back pain: integration of informed management principles into physical therapy practice - challenges and Opportunities. Phys Ther. 2011;91(5):790-803.

83. Nicholas MK, George SZ. Psychologically informed interventions for low back pain: an update for physical therapists. Phys Ther. 2011;91(5):765-776.

84. Ramond-Roquin A, Bouton C, Gobin-Tempereau A-S, et al. Interventions focusing on psychosocial risk factors for patients with non-chronic low back pain in primary care--a systematic review. Fam Pract. 2014;31(4):379-388.

85. Martel MO, Thibault P, Sullivan MJL. The persistence of pain behaviors in patients with chronic back pain is independent of pain and psychological factors. Pain. 2010;151(2):330-336.
86. Waddell G. Nonorganic signs. Spine (Phila Pa 1976). 2004;29(13):1393.

87. Prkachin KM, Hughes E, Schultz I, Joy P, Hunt D. Real-time assessment of pain behavior during clinical assessment of low back pain patients. Pain. 2002;95(1-2):23-30.

88. Keefe FJ, Smith S. The assessment of pain behavior: implications for applied psychophysiology and future research directions. Appl Psychophysiol Biofeedback. 2002;27(2):117-127.

89. Froud R, Patterson S, Eldridge S, et al. A systematic review and meta-synthesis of the impact of low back pain on people's lives. $B M C$ Musculoskelet Disord. 2014;15:50.

90. Shaw WS, Campbell P, Nelson CC, Main CJ, Linton SJ. Effects of workplace, family and cultural influences on low back pain: what opportunities exist to address social factors in general consultations? Best Pract Res Clin Rheumatol. 2013;27(5):637-648.

91. Muijzer A, Geertzen JH, de Boer WE, Groothoff JW, Brouwer S. Identifying factors relevant in the assessment of return-to-work efforts in employees on long-term sickness absence due to chronic low back pain: a focus group study. BMC Public Health. 2012;12:77.

92. Johnston V. Örebro musculoskeletal pain screening questionnaire. Aust J Physiother. 2009;55(2):141.

93. Fuhro FF, Fagundes FRC, Manzoni ACT, Costa LOP, Cabral $\mathrm{CMN}$. Örebro musculoskeletal pain screening questionnaire short-form and STarT back screening tool. Spine (Phila Pa 1976). 2016;41(15):E931-E936.

94. Melloh M, Elfering A, Chapple CM, et al. Prognostic occupational factors for persistent low back pain in primary care. Int Arch Occup Environ Health. 2013;86(3):261-269.

95. Melloh M, Elfering A, Stanton TR, et al. Who is likely to develop persistent low back pain? A longitudinal analysis of prognostic occupational factors. Work. 2013;46(3):297-311.

96. Stapelfeldt CM, Christiansen DH, Jensen OK, Nielsen CV, Petersen KD, Jensen C. Subgroup analyses on return to work in sick-listed employees with low back pain in a randomised trial comparing brief and multidisciplinary intervention. BMC Musculoskelet Disord. 2011;12:112.

97. Gross DP, Armijo-Olivo S, Shaw WS, et al. Clinical decision support tools for selecting interventions for patients with disabling musculoskeletal disorders: a scoping review. J Occup Rehabil. 2016;26(3): 286-318.

98. Qin Z, Armijo-Olivo S, Woodhouse LJ, Gross DP. An investigation of the validity of the Work Assessment Triage Tool clinical decision support tool for selecting optimal rehabilitation interventions for workers with musculoskeletal injuries. Clin Rehabil. 2016;30(3):277-287.

99. Fuentes J, Armijo-Olivo S, Funabashi M, et al. Enhanced therapeutic alliance modulates pain intensity and muscle pain sensitivity in patients with chronic low back pain: an experimental controlled study. Phys Ther. 2014;94(4):477-489.

100. Scholz J, Mannion RJ, Hord DE, et al. A novel tool for the assessment of pain: validation in low back pain. PLoS Med. 2009;6(4): e1000047.

101. Bialosky JE, Bishop MD, Price DD, Robinson ME, George SZ. The mechanisms of manual therapy in the treatment of musculoskeletal pain: a comprehensive model. Man Ther. 2009;14(5):531-538.

102. Butera KA, Fox EJ, George SZ. Toward a transformed understanding: from pain and movement to pain with movement. Phys Ther. 2016;96(10):1503-1507.

103. O'Sullivan P, Caneiro JP, O'Keeffe M, O'Sullivan K. Unraveling the complexity of low back pain. J Orthop Sport Phys Ther. 2016;46(11):932-937.

104. Rabey M, Smith A, Beales D, Slater H, O’Sullivan P. Differing psychologically derived clusters in people with chronic low back pain are associated with different multidimensional profiles. Clin J Pain. 2016;32(12):1015-1027.

105. Billis EV, McCarthy CJ, Oldham JA. Subclassification of low back pain: a cross-country comparison. Eur Spine J. 2007;16(7):865-879. 
The Journal of Pain Research is an international, peer reviewed, open access, online journal that welcomes laboratory and clinical findings in the fields of pain research and the prevention and management of pain. Original research, reviews, symposium reports, hypothesis formation and commentaries are all considered for publication
The manuscript management system is completely online and includes a very quick and fair peer-review system, which is all easy to use. Visit http://www.dovepress.com/testimonials.php to read real quotes from published authors. 